\title{
Influence of Dental Glass Fibers and Orthopedic Mesh on the Failure Loads of Polymethyl Methacrylate Denture Base Resin
}

\author{
Muhammad H. Rana ${ }^{1}$, Sharaz Shaik ${ }^{2}$ (D), Mohammad S. Hameed ${ }^{3}$, Samar Al-Saleh ${ }^{4}$, Eman M. AlHamdan ${ }^{4}$, \\ Abdullah Alshahrani ${ }^{4}$, Abdulaziz Alqahtani ${ }^{4}$, Ahmed Heji Albaqawi ${ }^{5}$, Fahim Vohra ${ }^{4,6}$ \\ and Tariq Abduljabbar 4,6,*D
}

1 Department of Prosthetic Dentistry, College of Dentistry, King Khalid University, Abha 61421, Saudi Arabia; haseebrana80@gmail.com

2 Department of Prosthetic Dentistry, Lenora Institute of Dental Sciences, Rajahmundry 533101, India; sharazshaik@gmail.com

3 Department of Diagnostic Sciences and Oral Biology, College of Dentistry, King Khalid University, Abha 61421, Saudi Arabia; mohammad.shahul@gmail.com

4 Department of Prosthetic Dental Sciences, College of Dentistry, King Saud University, Riyadh 11545, Saudi Arabia; Salsaleh@ksu.edu.sa (S.A.-S.); ealhamdan@ksu.edu.sa (E.M.A.); asalshahrani@ksu.edu.sa (A.A.); absalqahtani@ksu.edu.sa (A.A.); fvohra@ksu.edu.sa (F.V.)

5 Department of Restorative Dental Sciences, College of Dentistry, University of Hail, Hail 55476, Saudi Arabia; a.albaqawi@uoh.edu.sa

Citation: Rana, M.H.; Shaik, S.; Hameed, M.S.; Al-Saleh, S.; AlHamdan, E.M.; Alshahrani, A.; Alqahtani, A.; Albaqawi, A.H.; Vohra, F.; Abduljabbar, T. Influence of Dental Glass Fibers and Orthopedic Mesh on the Failure Loads of Polymethyl Methacrylate Denture Base Resin. Polymers 2021, 13, 2793. https:// doi.org/10.3390/polym13162793

Academic Editors: Abdul Majeed and Imran Farooq

Received: 26 July 2021

Accepted: 9 August 2021

Published: 20 August 2021

Publisher's Note: MDPI stays neutral with regard to jurisdictional claims in published maps and institutional affiliations.

Copyright: (c) 2021 by the authors Licensee MDPI, Basel, Switzerland. This article is an open access article distributed under the terms and conditions of the Creative Commons Attribution (CC BY) license (https:/ / creativecommons.org/licenses/by/ $4.0 /)$.
6 Eng. Abdullah Bugshan Research Chair for Dental and Oral Rehabilitation, College of Dentistry, King Saud University, Riyadh 11545, Saudi Arabia

* Correspondence: tajabbar@ksu.edu.sa; Tel.: +966-53875-4467

Abstract: The aim of the present study was to evaluate the fracture loads of polymethyl methacrylate (PMMA) complete denture bases reinforced with glass-fiber mesh and orthopedic casting tape (OCT) in comparison to conventional PMMA dentures under artificial aging. Dental fiberglass framework (Group 1) and OCT (Group 2 and 3) reinforced PMMA acrylic dentures were fabricated on the edentulous ridge. Ten PMMA dentures without reinforcement (Group 4) were included as controls. All specimens were placed in a chewing simulator chamber, and fatigue load was applied. To assess the fracture loads, static loads with a universal testing machine were applied. Fractured specimens in each group were evaluated under a scanning electron microscope. The data were statistically analyzed employing analysis of variance and Tukey post-hoc test. The association of denture weight and thickness on fracture load was assessed using Pearson and Spearman correlations. Dental fiberglass (Group 1) displayed the highest fracture load (692.33 $\pm 751.41 \mathrm{~N}$ ), and Group 4 (control) exhibited the lowest fracture loads $(281.41 \pm 302.51 \mathrm{~N})$. Dentures reinforced with fiberglass mesh framework exhibited intact fractures. In contrast, Group 2 and 3 specimens using OCT demonstrated ditching fractures. It was observed that the thickness and weight of all the reinforced specimens influenced the load required to fracture the dentures $(p<0.001)$. Denture specimens strengthened with OCT (Groups 2 and 3) exhibited failure loads lower than dental fiberglass (Group 1) specimens but higher than unreinforced controls.

Keywords: dental fiberglass framework; orthopedic casting tape; PMMA acrylic denture

\section{Introduction}

Heat and auto-polymerized polymethyl methacrylate (PMMA) acrylic resin are the most widely used material in the field of dentistry for prosthodontic and orthodontic appliances [1]. They are employed in a variety of restorations, i.e., complete, and partial dentures, provisional restorations or surgical aesthetic correction [2]. Excellent and pleasing esthetics, low water sorption, biocompatibility, ability to repair, manipulation ease and simple processing technique are some of the advantages of PMMA material that contribute to its success in clinical dentistry [3]. However, PMMA exhibits a compromise in mechanical 
and physical properties, i.e., low flexural strength (FS), low impact strength (IS) and low surface hardness, which leads to reduced clinical longevity of the prosthesis along with patient dissatisfaction [4]. The most common problem faced by the patients and dentist, associated with the PMMA denture bases, are fractures [5]. Johnston et al., revealed that nearly $68 \%$ of acrylic denture bases are fractured after a few years of fabrication, predominantly due to impact failure [6].

Forces usually responsible for resin denture prosthesis failures are flexural fatigue and impact force [7]. In order to overcome the mechanical shortcomings of PMMA dentures, different reinforcement methods have been adopted to improve their fatigue and fracture loads [8]. Initially, trials were conducted on the incorporation of metal wires and cast metal plates into PMMA acrylic resins $[9,10]$. However, a weak bond between the metal wires and acrylic resin was reported, resulting in poor mechanical properties of denture prosthesis [11]. In addition, incorporated metal plates undergo corrosion and form corrosion products causing decreased strength and potential staining of the denture [12]. Interestingly, the addition of organic and inorganic fibers to acrylic denture bases is also employed for resin reinforcement. Different fibers include Metal, Kevlar ${ }^{\circledR}$, glass, sapphire, polyester, carbon graphite and rigid polyethylene [13]. The incorporation of fibers in acrylic dentures improves the mechanical properties, i.e., transverse, tensile and impact strengths. Moreover, fiber reinforcement provides better esthetics and improved bonding to the resin when compared to other methods opted for reinforcement [14].

Among the different types of fibers used, glass fibers (GF) have gained much attention in the field of dentistry [15]. They are more esthetically pleasing, flexible and biocompatible when compared to other types of fibers, i.e., aramid carbon/graphite fibers that display poor aesthetics and weak bond with the acrylic resins [16]. Moreover, dentures using GF reinforcement are beneficial to the dental technician, dentist, and the patient, as they are fabricated in a short period of time and weigh less compared to the conventionally employed metal reinforcements. John et al., reported that glass, aramid or nylon fibers were effective in increasing the flexural strength of denture resins [17]. They also reported that among these fibers, glass-fiber-reinforced specimens, in particular, displayed the highest flexural strength [17]. Recently a few clinical studies have been conducted using glass fiber mesh as denture reinforcement for mechanical improvements. Fiber mesh is composed of e-glass fiber, and it is claimed that a denture reinforced with SES Fiber Mesh is three times stronger than a conventional denture without any reinforcement [18]. However, data related to the fracture load after reinforcing acrylic dentures with the glass fiber mesh is limited. Similarly, orthopedic casting tape (OCT) has been used for fracture management and ensures excellent outcomes of immobilization and rigid support in the field of orthopedics. However, their role in denture reinforcement has not been investigated.

From the available indexed literature, it was observed that data related to mechanical properties of complete dentures reinforced with glass-fiber mesh is inadequate. Moreover, the use of OCT for complete denture reinforcement is a novel concept in the reinforcement of PMMA acrylic resin denture bases. Therefore, it is hypothesized that PMMA acrylic resin denture bases reinforced with glass-fiber mesh and OCT will display better fracture loads when compared with the PMMA dentures bases without reinforcement. Thus, the aim of the present study was to evaluate the fracture strength of PMMA complete acrylic denture bases reinforced with glass-fiber mesh and OCT in comparison to conventional PMMA complete denture bases under artificial aging.

\section{Materials and Methods}

This study was submitted, reviewed, and approved by the center for specialist dentistry and research (UDRC/010-20). The ethical standards of the 1964 Helsinki declaration and national and/or institutional research committee were strictly followed while performing all the procedures. Forty PMMA stone-cast edentulous-standard denture base plates were prepared. Ten samples were prepared for each reinforcement of PMMA: acrylic with 
dental fiberglass framework (Group 1: SES Mesh), orthopedic cast tape (Group 2: Delta Lite Plus) and second orthopedic cast tape (Group 3: orthopedic casting tape). Ten samples were fabricated without reinforcing mesh using conventional heat-cured acrylic; these served as controls (Group 4). The study group details are presented in Table 1.

Table 1. Materials used for acrylic reinforcement in study groups.

\begin{tabular}{|c|c|}
\hline Study Groups & Materials for Reinforcement \\
\hline Group 1 & $\begin{array}{l}\text { Dental fiberglass framework, Group Z: SES Mesh, Inno dental } \\
\text { Co. Ltd., Seoul, Korea }\end{array}$ \\
\hline Group 2 & $\begin{array}{l}\text { Orthopedic casting tape, Delta Lite Plus, BSN medical } \\
\text { GMBH., Frankfurt, Germany }\end{array}$ \\
\hline Group 3 & $\begin{array}{l}\text { Orthopedic casting tape 2, Shanghai Nineluck Co. Ltd., } \\
\text { Beijing, China }\end{array}$ \\
\hline Group 4 (control) & $\begin{array}{l}\text { Heat Cure acrylic no reinforcements Meliodent Heat Cure, } \\
\text { Kulzer GmbH., Frankfurt, Germany }\end{array}$ \\
\hline
\end{tabular}

\subsection{Master Cast Preparation}

Forty edentulous maxillary models were fabricated with type 3 dental stone (Durguix, Protechno, Spain.) using an edentulous silicon mold (EDE1001-UL-MO, Nissin Dental Products Inc., Kyoto, Japan). Model surface discrepancies were removed.

\subsection{Acrylic Denture Base Fabrication}

All prepared stone casts were treated with two layers of separating medium (Cold molsem d seal- Aqua seal, India) prior to waxing up for denture fabrication. For the wax-up of acrylic resin denture samples, in each group, two layers of $1.0 \mathrm{~mm}$ thick wax sheets (Preparation wax, BEGO Bremer Goldschlägerei Wilh. Herbst GmbH \& Co. KG, Frankfurt, Germany) was adapted onto the functional cast area. Stops $2 \mathrm{~mm}$ wide and $5 \mathrm{~mm}$ long were created by removing wax in the canine, first molar regions bilaterally and in the mid-palatal region. The stops were filled with flowable resin composite (Premise flowable composite (Kerr, Corp, Orange, CA, USA) and light-cured with a dental light-curing unit (SES Curing Unit, Inno dental Co. Ltd., Seoul, Korea). The reinforcing mesh in respective study groups was adapted over the entire wax sheet, $2 \mathrm{~mm}$ short of the vestibule and posterior palatal seal area (posterior border). The mesh was adapted into the cutout wax tops to secure them. The adaptations for all mesh reinforcements were performed with a vacuum apparatus (SES vacuum unit, Inno dental Co. Ltd., Seoul, Korea). The mesh in Group 1 specimens was light polymerized using a standard curing system (SES Curing Unit, Inno dental Co. Ltd., Seoul, Korea). However, the OCT among Group 2 and Group 3 specimens was water sprayed and adapted manually, followed by vacuum adaptation. The casting tapes (Groups 2 and 3) were auto-polymerized for $8 \mathrm{~h}$. The reinforcing mesh and casting tapes among Groups 1, 2 and 3 were secured to the resin stops with cyanoacrylate, preventing the displacement of the mesh during acrylic resin dough packing in denture processing. The reinforcement meshes were covered with two sheets of $1.0 \mathrm{~mm}$ preparation wax, followed by adaptation among all groups. Among Group 4 specimens (controls), no reinforcement mesh was placed, and two sheets of $1.0 \mathrm{~mm}$ preparation wax were applied and adapted.

\subsection{Processing of Denture Plates}

All the waxed-up specimens were developed with dental stone within the dental flask. After the complete setting of stone plaster, flasks were dewaxed. The wax left on the stone surface after dewaxing was flushed away with the help of boiling water. The mold space obtained after dewaxing was then used to fabricate the test specimens. The molds were left open, air-dried and cooled at room temperature. A separating agent (cold mold seal; Dental products of India, DPI) was smeared on the surface and dried. Heat cure acrylic 
was mixed following the manufacturer's guidelines and packed in the flasks at the dough stage. All the flasks were placed in the hydraulic press (Sirio Dental, Meldola, Italy), and the entire mold and clamp assembly was placed in the curing unit (Wassermann DentalMaschinen $\mathrm{GmbH}$, Hamburg, Germany), maintaining $72{ }^{\circ} \mathrm{C}$ temperature for almost 90 min and $95{ }^{\circ} \mathrm{C}$ for $30 \mathrm{~min}$. Prior to deflasking, the flasks were cooled at room temperature for $30 \mathrm{~min}$ to release the stresses. The dentures were recovered from the flask and finished with a series of silicon carbide papers (Buehler Ltd., Esslingen, Germany). The surface of the specimens was polished and smoothened using a lapping machine (MetaServ 250, Buehler Ltd., Esslingen, Germany). Figure 1 shows the mesh applications and processed PMMA resin denture plates. The weight $(\mathrm{gm})$ and thickness $(\mathrm{mm})$ of each denture were measured after finishing and polishing.

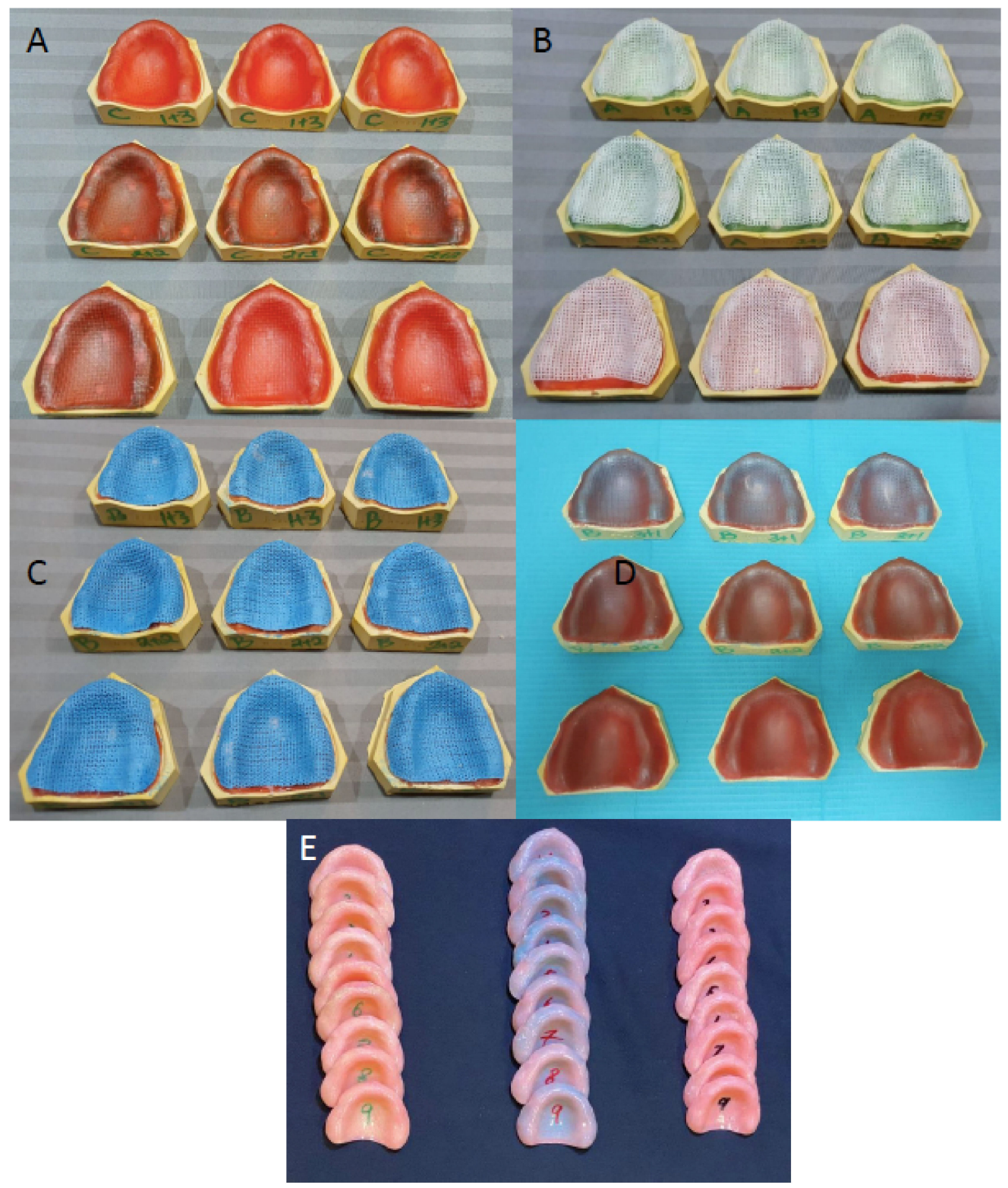

Figure 1. PMMA resin reinforcement mesh groups. Group 1. Dental fiberglass framework reinforcement (A). Group 2. Orthopedic casting tape, Delta Lite Plus reinforcement (B). Group 3. Orthopedic casting tape, Shanghai Nineluck reinforcement (C). Wax up of all reinforced groups (D). Processed dentures (E). 


\subsection{Fatigue Load Application}

All specimens were artificially aged by thermocycling for 50,000 cycles between $5{ }^{\circ} \mathrm{C}$ and $55^{\circ} \mathrm{C}$ water baths at a dwelling time of $10 \mathrm{~s}$. All specimens were placed in a chewing simulator chamber and exposed to 10,000 cycles at $20 \mathrm{~N}$ load in distilled water. The opposing loading surface was in the form of acrylic resin balls of $15 \mathrm{~mm}$ diameter (Meliodent Heat Cure, Kulzer GmbH, Frankfurt, Germany) [19], contacting the anterior palatal slopes.

\subsection{Fracture Testing}

All denture plates were assessed for fracture loads in Newton $(\mathrm{N})$. The denture plates were secured on a customized metal stage and a controlled continuous load was applied on the anterior palatal slope of the plate with a customized half-round (10 $\mathrm{mm}$ diameter) metal probe. Static compressive loads were applied at a crosshead speed of $1 \mathrm{~mm} / \mathrm{min}$. The fracture testing setup is shown in Figure 2.

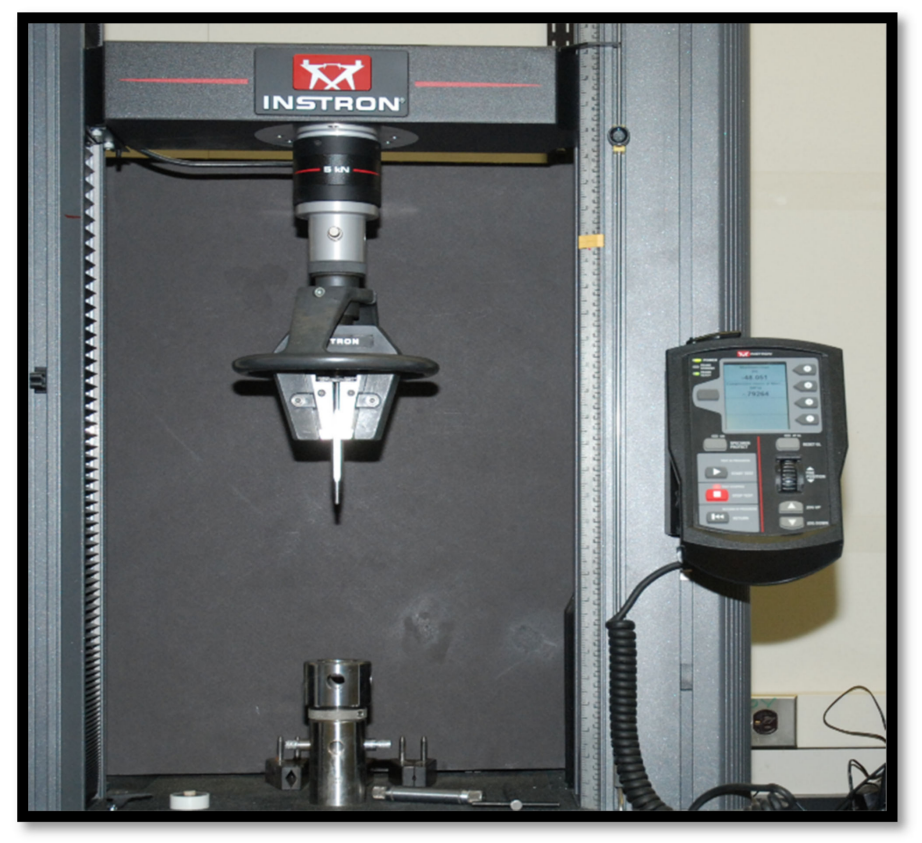

Figure 2. Testing equipment (Instron testing machine) used for denture fractures.

Four fractured specimens in each group were evaluated under scanning electron microscopy (SEM) (JSM-6513, JEOL, Tokyo, Japan). The fractured resin surface was prepared by placement on aluminum stubs and sputter coating with gold for 2 min (Baltec SCD sputter, Scotia, NY, USA). The assessments and evaluations were made at an accelerating voltage of $30 \mathrm{kV}$ utilizing SEM. SEM micrographs of the specimens were obtained at multiple magnifications for qualitative assessment of the fracture surfaces showing the reinforcing mesh and casting tapes. The data were statistically analyzed by statistical software (Version 20, SPSS Inc., Chicago, IL, USA) employing analysis of variance (ANOVA) and Tukey post-hoc multiple comparison test. The association of denture weight and thickness to fracture loads was assessed using Pearson and Spearman correlations.

\section{Results}

The fracture loads of PMMA acrylic resin plates are presented in Table 2. Group 1 (dental fiberglass framework) displayed the highest fracture loads $(692.33 \pm 75.41 \mathrm{~N})$, and Group 4 (control) exhibited the lowest fracture loads (281.41 $\pm 30.51 \mathrm{~N})$. ANOVA revealed a statistically significant difference in fractural load outcome among the different tested groups $(p<0.001)$. Furthermore, individual group comparison established that Group 1 displayed higher fracture loads than Group 2 (Orthopedic casting tape, Delta Lite Plus, 
BSN medical GMBH, Frankfurt, Germany) (487.40 \pm 51.72 N), Group 3 (Orthopedic casting tape, Shanghai Nineluck Co. Ltd., Shanghai, China) (486.94 \pm 52.39 N) and Group 4 specimens. Specimens in Groups 2 and 3 exhibited fracture loads higher than control specimens $(p<0.05)$ and comparable among themselves $(p>0.05)$.

Table 2. Means, SD and statistical comparison of fracture loads among study groups.

\begin{tabular}{|c|c|c|c|c|c|c|c|}
\hline Group & Mean (N) & SD (N) & $\begin{array}{l}\text { ANOVA } \\
p \text {-Value }\end{array}$ & $\begin{array}{c}\text { Kruskal-Wallis } \\
p \text {-Value }\end{array}$ & $\begin{array}{c}\text { Group } \\
\text { Comparison }\end{array}$ & Z-Value & $\begin{array}{c}\text { Adjusted } \\
p \text {-Value }\end{array}$ \\
\hline \multirow{2}{*}{1} & \multirow{2}{*}{692.33} & \multirow{2}{*}{75.41} & \multirow{6}{*}{$<0.001$} & \multirow{6}{*}{$<0.001$} & 2 vs. 3 & -2.27 & 0.03 \\
\hline & & & & & 2 vs. 4 & 2.59 & 0.02 \\
\hline 2 & 487.40 & 51.72 & & & 3 vs. 4 & 4.86 & 0.00 \\
\hline \multirow{2}{*}{3} & \multirow{2}{*}{486.94} & \multirow{2}{*}{52.39} & & & 1 vs. 2 & 0.02 & 0.99 \\
\hline & & & & & 1 vs. 3 & -2.26 & 0.03 \\
\hline 4 & 281.41 & 30.51 & & & 1 vs. 4 & 2.61 & 0.03 \\
\hline
\end{tabular}

Group 1: Dental fiberglass framework, SES Mesh, Inno dental Co. Ltd., Korea. Group 2: Orthopedic casting tape, Delta Lite Plus, BSN medical GMBH, Germany. Group 3: Orthopedic casting tape, Shanghai Nineluck Co. Ltd., China. Group 4: Heat Cure acrylic with no reinforcements (control). $p$-value: significance set at $\alpha=0.05$. $Z$-value: standard score.

The fractured specimens of reinforced groups are presented in Figure 3. The images showed that dentures reinforced with fiberglass mesh framework (group 1) exhibited intact failures (Figure 3A,B). Whereas Group 2 and 3 specimens, using OCT, demonstrated ditching fractures (Figure 3C,D). The correlation between thickness and weight of reinforced and non-reinforced acrylic dentures with the failure loads among the different experimental groups is presented in Table 3. It was found that the thickness and weight of all the reinforced specimens influenced the load required to fracture the dentures $(p<0.05)$.

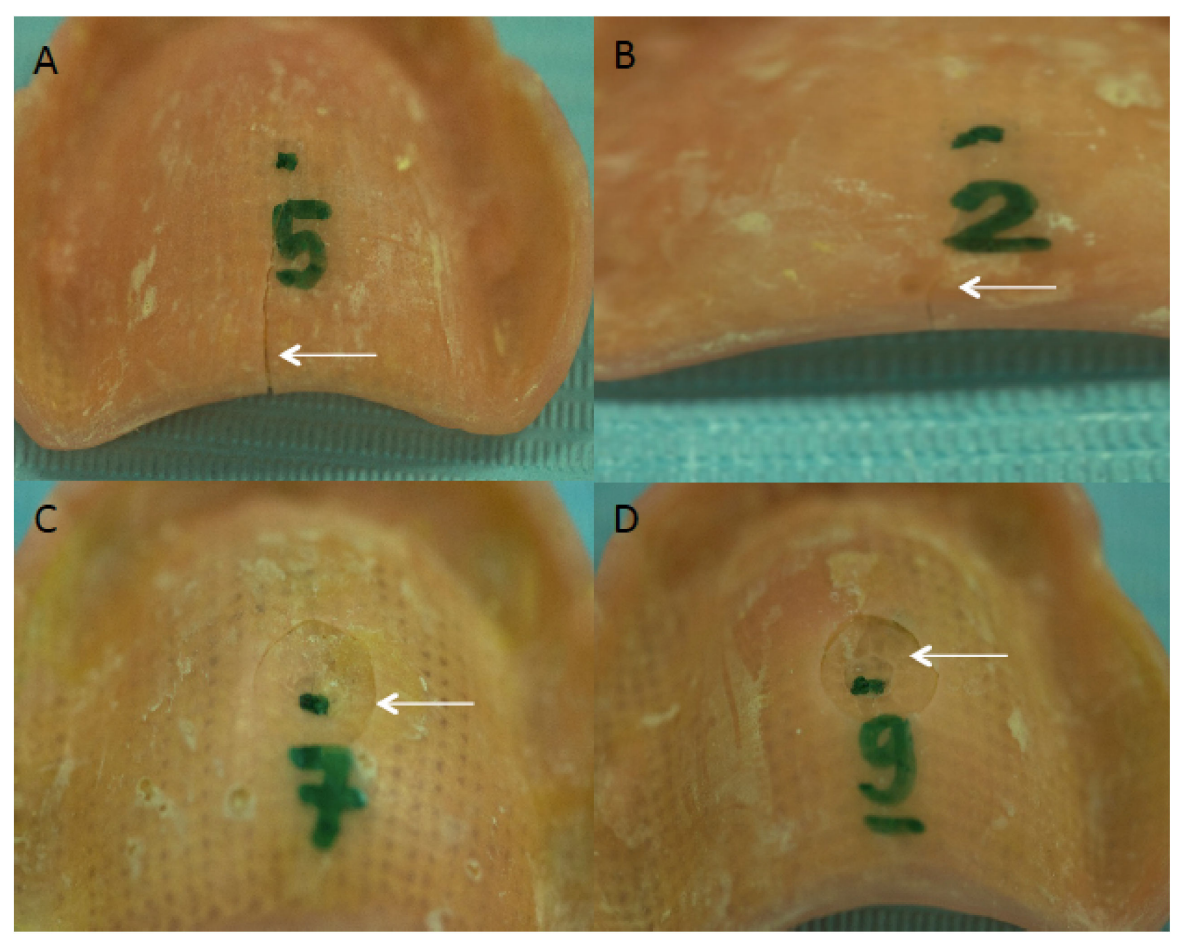

Figure 3. Fracture patterns of the PMMA resin plate samples in the study groups. (A,B), Showing straight line intact fracture patterns in Group 1 specimens. (C,D), Fractured specimens showing ditched fractures in specimens of Group 2 and Group 3, respectively. 
Table 3. Correlation of thickness and weight of the specimens with the failure loads among the groups.

\begin{tabular}{ccccc}
\hline Variable & $\begin{array}{c}\text { Pearson } \\
\text { CC }\end{array}$ & $\begin{array}{c}\text { Pearson } \\
\boldsymbol{p} \text {-Value }\end{array}$ & $\begin{array}{c}\text { Spearma } \\
\text { CC }\end{array}$ & $\begin{array}{c}\text { Spearman } \\
\boldsymbol{p} \text {-Value }\end{array}$ \\
\hline Thickness & 0.751 & $<0.001$ & 0.822 & $<0.001$ \\
\hline Weight & 0.812 & $<0.001$ & 0.862 & $<0.001$ \\
\hline
\end{tabular}

CC: correlation coefficient.

SEM images of acrylic denture reinforced with Dental fiberglass framework are presented in Figure 4. A bundle of reinforcing fibers was observed at $30 \times$ magnification, with an approximate length of $2.5 \mathrm{~mm}$ (Figure $4 \mathrm{~A}$ ). In addition, flat and irregular fiberglass bundle fibers demonstrating rounded edges were observed $(\times 100)$ (Figure $4 \mathrm{~B})$. Figure $3 \mathrm{C}$ presented a high magnification image of dental fiberglass unidirectional glass fibers embedded in a resin matrix $(\times 1000)$ (Figure $4 \mathrm{C})$. Figure 5 presents SEM images of OCT fibers observed at different magnifications. A bundle of fibers was observed with elevated margins, measuring approximately $500 \times 200$ um (Figure 5A,B). A honeycomb-pattern bundle of glass fibers with closely staked fibrils and comparatively few empty spaces around the individual fibers was appreciated $(\times 100)$ (Figure 5 C). Figure 6 presents SEM images of OCT used in Group 3 at magnifications of $\times 30, \times 100$ and $\times 1000$. A bundle of fibers with raised boundaries having an estimated length of $1500 \mathrm{um}$ was detected (Figure 6A,B). At higher magnification, individual elongated and parallel micro-fibers with scant matrices were observed $(\times 1000)$. Individual fibrils were densely packed, flat and interconnected (Figure 6C).

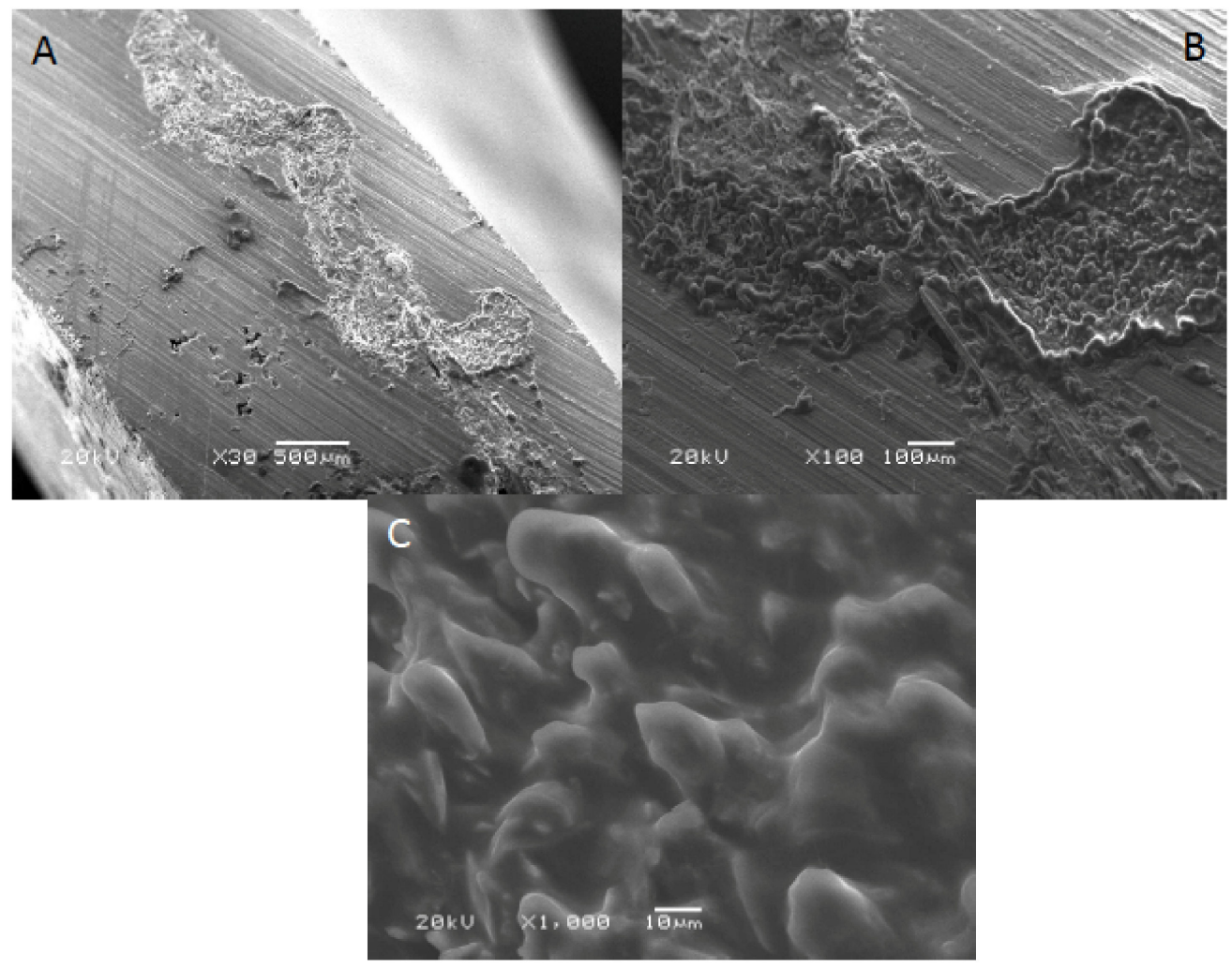

Figure 4. SEM images of acrylic denture reinforced with dental fiberglass framework (group 1) at (A) $\times 30,(B) \times 100$ and $(\mathbf{C}) \times 1000$ magnification. 


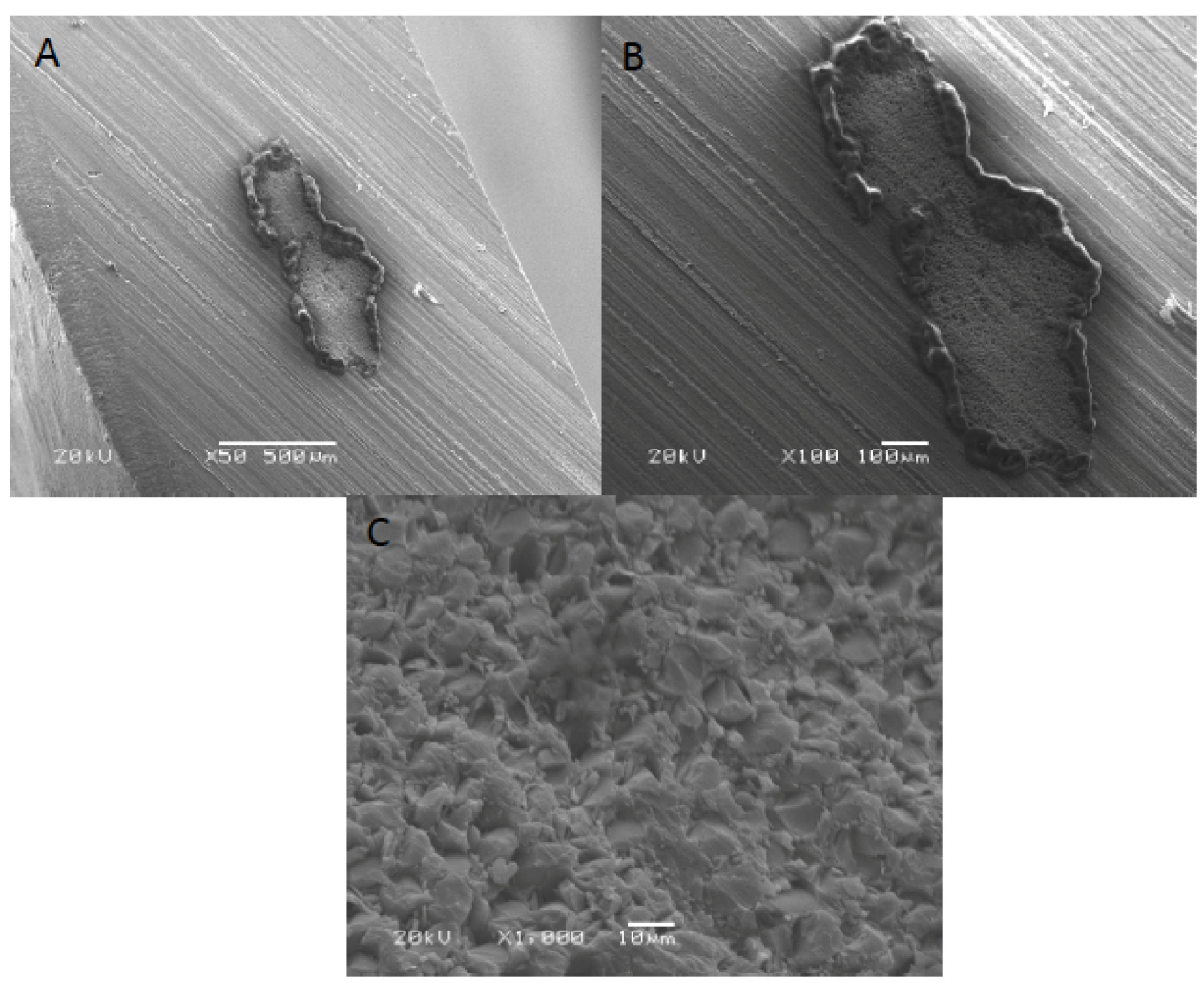

Figure 5. SEM images of OCT fibers (group 2$)$ at $(\mathbf{A}) \times 50,(\mathbf{B}) \times 100$ and $(\mathbf{C}) \times 1000$ magnification.

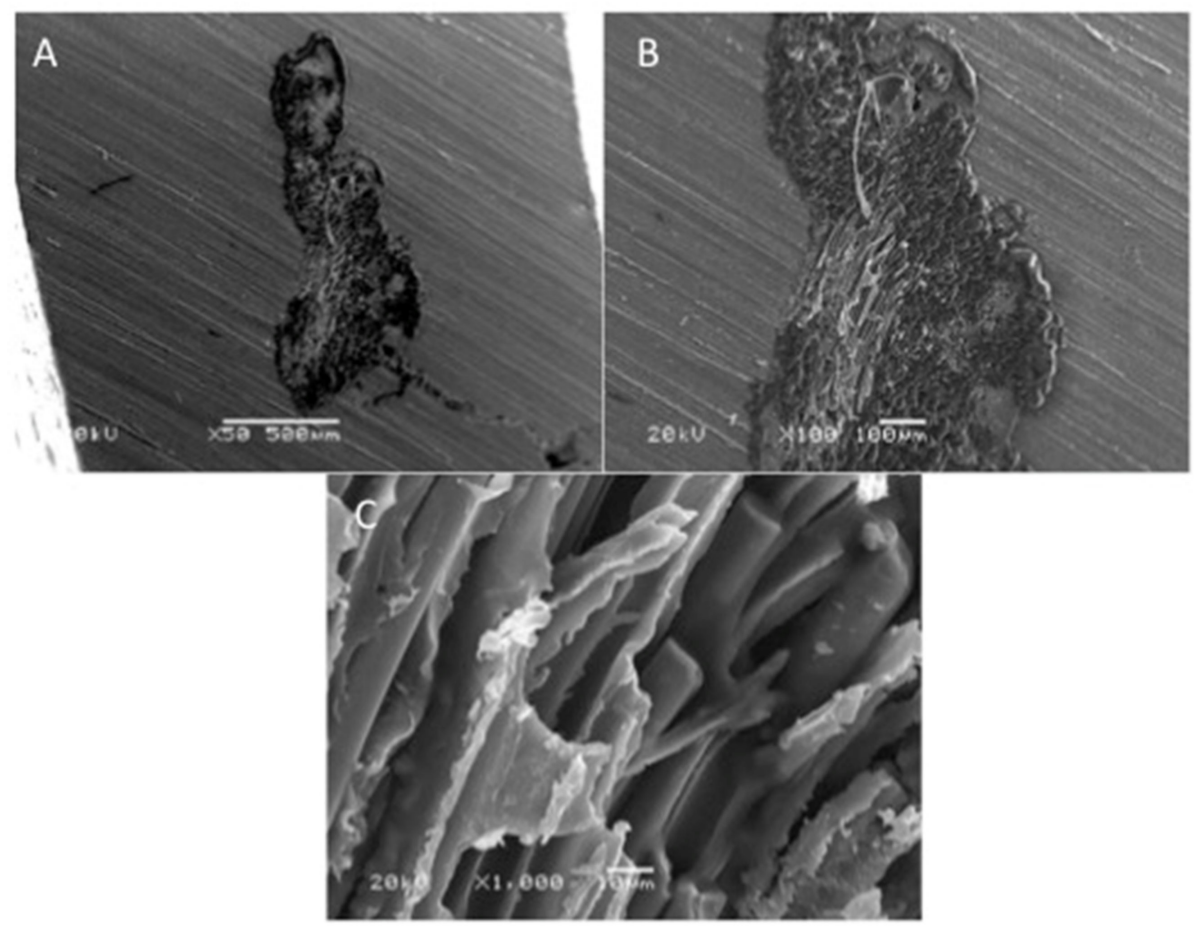

Figure 6. SEM images of OCT fibers (group 3$)$ at $(\mathbf{A}) \times 30,(\mathbf{B}) \times 100$ and $(\mathbf{C}) \times 1000$ magnification.

\section{Discussion}

The present in vitro study was based on the hypothesis that complete acrylic dentures reinforced with a glass-fiber mesh and OCT display better fracture and failure loads when compared to dentures without any reinforcement (control) in a model simulating oral 
conditions. The use of glass fiber and OCT showed a significant improvement in the failure loads of PMMA resin denture plates compared to controls; therefore the hypothesis was accepted.

A strong denture base is required for clinical longevity, biologically acceptability and aesthetically pleasing outcomes $[15,20]$. The literature revealed that an adult human with an intact dentition usually exerts a 300 to $700 \mathrm{~N}$ dynamic masticatory load [21,22]. The force required to fracture non reinforced denture is around $706 \mathrm{~N}$, while reinforced denture bases required $903 \mathrm{~N}$ of masticatory force, which is much greater than the force required to fracture the denture $[17,23]$. Moreover, it was also found that the oral environment influences the threshold for denture fractures intraorally. Therefore the study employed the use of thermocycling and chewing simulation to closely simulate the oral environment for testing failure loads of experimental denture plates [24].

The literature revealed that fracture loads of reinforced acrylic denture prostheses are dependent on the mechanical properties of the material used $[25,26]$. Studies have suggested that glass fibers efficiently influence the mechanical strength of the acrylic denture bases $[15,27]$. However, certain factors, i.e., fiber type, diameter and length of the fiber, fiber resin ratio, orientation and location of the fiber, affect the reinforcement properties of different fibers used [28]. The dental fiberglass mesh and OCT used in the present study is a combination of strong glass fibers, substrate and resin [29]. In the present study, the dental fiberglass framework (group 1) demonstrated the highest fracture loads $(692.33 \pm 75.41 \mathrm{MPa})$. Group 4 specimens with no reinforcement displayed the lowest fracture loads ( $281.41 \pm 30.51 \mathrm{MPa}$ ) when compared to all the experimental groups.

In the present study, it was found that both OCT and fiberglass mesh are effective in strengthening the acrylic denture bases; this is due to the presence of glass fibers in the resin matrix. This is in line with the outcomes of the study conducted by Yu et al. [29]. However, differences in the flexural strength among reinforced investigated groups may be due to the differences in the distribution of glass fibers and their adhesion with the heatactivated acrylic resin [30]. Moreover, it can be assumed that different fiber orientations in tested groups may also be responsible for the difference in fracture loads of reinforced dentures [31]. It is also suggested that the most preferred OCTs consist of a minimum of $50 \%$ to $70 \%$ of filler content [32]. In addition, the authors predicted that the difference in fracture load among the two OCT groups might be due to the difference in fiber concentration.

In the present study, it was observed that the weight and thickness of the PMMA resin denture plates influence their fracture loads. This is in line with the outcomes of previous studies, which reported that $57 \%$ to $64 \%$ of acrylic resin denture fractures occur at the site of the least thickness of specimen $[33,34]$. Since biomechanical stresses are focused on these areas, it can be concluded that the increased thickness and weight of acrylic dentures affect the mechanical properties of dentures [35].

SEM analysis revealed detectable variations among the matrix and fiber morphology and configuration among materials. Material morphology was influenced by the orientation and concentration of fibers used. It was found that the dental fiberglass in Group 1 specimens showed a greater resin matrix with longer and larger fibers when compared to Groups 2 and 3 OCT reinforced PMMA dentures, justifying the greater flexural load in this group [13]. Similarly, it was also found that specimens in Group 1 showed intact fractures compared to Groups 2 and 3 specimens, which presented ditching fractures, thus confirming the higher fracture loads of Group 1 specimens.

The present study suggests the incorporation of orthopedic casting tapes and dental fiberglass to improve the fracture loads of PMMA acrylic dentures. However, these findings should be considered in light of the fact that the present study was in vitro, palatal load application in contrast to neutral zone load application was used and lateral loading was not performed. In addition, the impact of colored glass fibers on the aesthetic appearance of the prosthesis was not considered in the present study. Therefore, further long-term randomized controlled trials to assess the performance of PMMA resin-complete dentures reinforced with orthopedic casting tape and dental fiberglass are warranted. 


\section{Conclusions}

Dental fiberglass reinforced PMMA dentures (Group 1) displayed the highest fracture loads among the study groups. Dentures without any fiber reinforcement (Group 4) exhibited the lowest fracture load. Denture specimens strengthened with OCT (Groups 2 and 3) exhibited failure loads lower than dental fiberglass (Group 1) specimens but higher than unreinforced controls. The thickness and weight of all the reinforced specimens influence the load required to fracture the dentures.

Author Contributions: Conceptualization, M.H.R., S.S., A.A. (Abdullah Alshahrani), A.H.A. and M.S.H.; methodology, M.H.R., S.S., E.M.A., T.A., A.H.A., A.A. (Abdulaziz Alqahtani) and M.S.H.; validation, M.H.R., A.A. (Abdullah Alshahrani), S.S., F.V., M.S.H. and T.A. formal analysis, S.S., E.M.A., S.A.-S., A.A. (Abdulaziz Alqahtani), A.H.A.; investigation, S.S., E.M.A., S.A.-S., A.A. (Abdullah Alshahrani) and F.V.; resources, T.A., S.A.-S., E.M.A., A.H.A., A.A. (Abdulaziz Alqahtani), A.A. (Abdullah Alshahrani); data curation, M.H.R., S.S., A.A. (Abdullah Alshahrani), A.A. (Abdullah Alshahrani), A.H.A. and S.A.-S.; writing-original draft preparation, F.V., S.A.-S., A.A. (Abdullah Alshahrani), A.A. (Abdulaziz Alqahtani) and T.A.; writing-review and editing, T.A., S.A.-S., M.H.R., A.H.A., A.A. (Abdullah Alshahrani) and M.S.H.; supervision, F.V. and T.A.; funding acquisition, T.A. All authors have read and agreed to the published version of the manuscript.

Funding: The authors are grateful to the Deanship of Scientific Research, King Saud University, for funding through Vice Deanship of Scientific Research Chairs and Abdullah Bugshan, research chair for Dental and Oral Rehabilitation.

Institutional Review Board Statement: This study was submitted, reviewed, and approved by the center for specialist dentistry and research (UDRC/010-20). The ethical standards of the 1964 Helsinki declaration and national and/or institutional research committee were strictly followed while performing all the procedures. Informed written consent was obtained from each subject before conducting any procedures. Additional information on the study was provided verbally by the study investigator or in a written format.

Informed Consent Statement: Informed written consent was obtained from each subject before conducting any procedures. Additional information on the study was provided verbally by the study investigator or in a written format.

Data Availability Statement: The data is available on contact with the corresponding author.

Acknowledgments: The authors are grateful to the Deanship of Scientific Research, King Saud University, for funding through Vice Deanship of Scientific Research Chairs and Engnr Abdullah Bugshan, research chair for Dental and Oral Rehabilitation. The research was supported by the Deanship of Scientific Research, King Khalid University, Abha, Saudi Arabia (Project Number G.R.P-52-31).

Conflicts of Interest: The authors declare no conflict of interest.

\section{References}

1. Karci, M.; Demir, N.; Yazman, S. Evaluation of Flexural Strength of Different Denture Base Materials Reinforced with Different Nanoparticles. J. Prosthodont. 2019, 28, 572-579. [CrossRef]

2. Zafar, M.S. Prosthodontic applications of polymethyl methacrylate (PMMA): An update. Polymers 2020, 12, 2299. [CrossRef] [PubMed]

3. Rahal, J.S.; Mesquita, M.F.; Henriques, G.E.P.; Nóbilo, M.A.A. Surface roughness of acrylic resins submitted to mechanical and chemical polishing. J. Oral Rehabil. 2004, 31, 1075-1079. [CrossRef] [PubMed]

4. Phoenix, R.D. Denture base materials. Dent. Clin. N. Am. 1996, 40, 113-120. [PubMed]

5. Gul, H.; Aslam, A.; Nayyer, M.; Kaleem, M. Possible errors in acrylic denture fabrication leading to teeth-denture base interface failure. Pak. Oral Dent. J. 2017, 37, 510-515.

6. Johnston, E.P.; Nicholls, J.I.; Smith, D.E. Flexure fatigue of 10 commonly used denture base resins. J. Prosthet. Dent. 1981, 46, 478-483. [CrossRef]

7. Han, S.Y.; Moon, Y.H.; Lee, J. Shear bond strength between CAD/CAM denture base resin and denture artificial teeth when bonded with resin cement. J. Adv. Prosthodont. 2020, 12, 251-258. [CrossRef]

8. Prajwala, N.; Ravi Kumar, C.; Sujesh, M.; Chalapathi Rao, D.; Pavani, L. Denture base reinforcing materials-A review. IP Ann. Prosthodont. Restor. Dent. 2020, 6, 52-59. [CrossRef] 
9. Teraoka, F.; Nakagawa, M.; Takahashi, J. Adaptation of acrylic dentures reinforced with metal wire. J. Oral Rehabil. 2001, 28, 937-942. [CrossRef]

10. Transverse Strength of Reinforced Denture Base Resin with Metal Wire and E-Glass Fibers. Available online: https: //www.researchgate.net/publication/228357826_Transverse_Strength_of_Reinforced_Denture_Base_Resin_with_Metal_ Wire_and_E-Glass_Fibers (accessed on 21 June 2021).

11. Kanie, T.; Arikawa, H.; Fujii, K.; Ban, S. Color change in acrylic denture base resin reinforced with wire mesh and glass cloth Dent. Mater. J. 2003, 22, 425-435. [CrossRef]

12. Somani, M.V.; Khandelwal, M.; Punia, V.; Sharma, V. The effect of incorporating various reinforcement materials on flexural strength and impact strength of polymethylmethacrylate: A meta-analysis. J. Indian Prosthodont. Soc. 2019, 19, 101-112. [CrossRef] [PubMed]

13. Alla, R.K.; Sajjan, S.; Alluri, V.R.; Ginjupalli, K.; Upadhya, N. Influence of Fiber Reinforcement on the Properties of Denture Base Resins. Biomater. Nanobiotechnol. 2013, 4, 91-97. [CrossRef]

14. Gad, M.M.; Fouda, S.M.; Al-Harbi, F.A.; Näpänkangas, R.; Raustia, A. PMMA denture base material enhancement: A review of fiber, filler, and nanofiller addition. Int. J. Nanomed. 2017, 12, 3801-3812. [CrossRef]

15. Goguaţă, L.M.; Bratu, D.; Jivănescu, A.; Erimescu, R.; Mărcăuaţeanu, C. Glass fibre reinforced acrylic resin complete dentures: A 5-year clinical study. Gerodontology 2012, 29, 64-69. [CrossRef]

16. Larson, W.R.; Dixon, D.L.; Aquilino, S.A.; Clancy, J.M.S. The effect of carbon graphite fiber reinforcentent on the strength of provisional crown and fixed partial denture resins. J. Prosthet. Dent. 1991, 66, 816-820. [CrossRef]

17. John, J.; Gangadhar, S.A.; Shah, I. Flexural strength of heat-polymerized polymethyl methacrylate denture resin reinforced with glass, aramid, or nylon fibers. J. Prosthet. Dent. 2001, 86, 424-427. [CrossRef] [PubMed]

18. Yu, S.H.; Cho, H.W.; Oh, S.; Bae, J.M. Effects of glass fiber mesh with different fiber content and structures on the compressive properties of complete dentures. J. Prosthet. Dent. 2015, 113, 636-644. [CrossRef]

19. Heintze, S.D.; Eser, A.; Monreal, D.; Rousson, V. Using a chewing simulator for fatigue testing of metal ceramic crowns. J. Mech. Behav. Biomed. Mater. 2017, 65, 770-780. [CrossRef]

20. AlHelal, A.; AlRumaih, H.S.; Kattadiyil, M.T.; Baba, N.Z.; Goodacre, C.J. Comparison of retention between maxillary milled and conventional denture bases: A clinical study. J. Prosthet. Dent. 2017, 117, 233-238. [CrossRef] [PubMed]

21. Murray, M.D.; Darvell, B.W. The evolution of the complete denture base. Theories of complete denture retention-A review. Part 1. Aust. Dent. J. 1993, 38, 216-219. [CrossRef]

22. Cunningham, J.L.; Benington, I.C. An investigation of the variables which may affect the bond between plastic teeth and denture base resin. J. Dent. 1999, 27, 129-135. [CrossRef]

23. Chen, J.C.; Lacefield, W.R.; Castleberry, D.J. Effect of denture thickness and curing cycle on the dimensional stability of acrylic resin denture bases. Dent. Mater. 1988, 4, 20-24. [CrossRef]

24. Sarikaya, I.; Hayran, Y. Effects of dynamic aging on the wear and fracture strength of monolithic zirconia restorations. BMC Oral Health 2018, 18, 146. [CrossRef]

25. Jagger, D.C.; Harrison, A.; Jandt, K.D. The reinforcement of dentures. J. Oral Rehabil. 1999, 26, 185-194. [CrossRef] [PubMed]

26. Vallittu, P.K. Flexural properties of acrylic resin polymers reinforced with unidirectional and woven glass fibers. J. Prosthet. Dent. 1999, 81, 318-326. [CrossRef]

27. Vallittu, P.K. Glass fiber reinforcement in repaired acrylic resin removable dentures: Preliminary results of a clinical study. Quintessence Int. 1997, 28, 39-44. [PubMed]

28. Narva, K.K.; Vallittu, P.K.; Helenius, H.; Yli-Urpo, A. Clinical Survey of Acrylic Resin Removable Denture Repairs with Glass-Fiber Reinforcement. Int. J. Prosthodont. 2001, 14, 219-224.

29. Stipho, H.D. Repair of acrylic resin denture base reinforced with glass fiber. J. Prosthet. Dent. 1998, 80, 546-550. [CrossRef]

30. Vijay, A.; Prabhu, N.; Balakrishnan, D.; Narayan, A.I. Comparative study of the flexural strength of high impact denture base resins reinforced by silver nanoparticles and e-glass fibres: An in-vitro study. J. Clin. Diagn. Res. 2018, 12, 22-26. [CrossRef]

31. Kim, S.H.; Watts, D.C. The effect of reinforcement with woven E-glass fibers on the impact strength of complete dentures fabricated with high-impact acrylic resin. J. Prosthet. Dent. 2004, 91, 274-280. [CrossRef]

32. Glass Fiber Reinforced Polymer (GFRP)—Technology in Architecture. Available online: https://technologyinarchitecture. wordpress.com/2018/06/30/glass-fiber-reinforced-polymer-gfrp/ (accessed on 22 June 2021).

33. Sekinishi, T.; Inukai, S.; Murakami, N.; Wakabayashi, N. Influence of denture tooth thickness on fracture mode of thin acrylic resin bases: An experimental and finite element analysis. J. Prosthet. Dent. 2015, 114, 122-129. [CrossRef] [PubMed]

34. Choi, M.; Acharya, V.; Berg, R.W.; Marotta, J.; Green, C.C.; Barbizam, J.V.; White, S.N. Resinous denture base fracture loads: Effects of thickness and teeth. Int. J. Prosthodont. 2012, 25, 53-59. [PubMed]

35. Żmudzki, J.; Chladek, G.; Kasperski, J. Biomechanical factors related to occlusal load transfer in removable complete dentures. Biomech. Model. Mechanobiol. 2015, 14, 679-691. [CrossRef] [PubMed] 